\title{
Análise faciológica e interpretação palinológica de testemunho recuperado de ambiente lacustre assoreado no Parque Estadual do Rio Doce (MG)
}

\author{
Clayton Perônico ${ }^{1}$ \& Paulo de Tarso Amorim Castro ${ }^{2}$
}

\begin{abstract}
Resumo Este trabalho descreve as fácies sedimentares identificadas para um depósito lacustre localizado no médio vale do rio Doce, leste do Estado de Minas Gerais e traça uma interpretação para a fase final do processo deposicional. Um testemunho de 1,65 m foi recuperado (LPERD), onde três fácies foram identificadas, com predomínio da fração argila indicando que o processo envolveu baixa energia. Todas as fácies identificadas em LPERD podem ser agrupadas em um conjunto maior de fácies deposicionais propriamente ditas. A associação I foi interpretada como um ambiente com ligeira diminuição da energia de deposição, enquanto na associação II, possivelmente, ocorreu uma diminuição mais significativa. Ambas as associações, no entanto, não descartam a possibilidade de todo o processo deposicional ter ocorrido em um ambiente alagado. A análise palinológica da fácies Fma (topo) permitiu uma interpretação preliminar da fase final do processo de deposição. Foram identificados dois tipos de algas, cinco tipos de fitoclastos, um tipo de esporo de fungo, três tipos de esporos de pteridófitas e 11 tipos de grãos de pólen de angiospermas. Os pólens encontrados pertencem à táxons de ocorrência registrada para a Floresta Estacional Semidecídua Submontana. As algas identificadas pertencem às espécies Botryococcus braunii e Spirogyra sp. que ocupam pântanos rasos, solos encharcados ou úmidos, além de, turfeiras características típicas de ambiente palustre. O registro de esporos de fungos é indicativo de solos orgânicos, anóxicos, onde o processo de decomposição foi interrompido ou ocorre de maneira muito lenta. As informações reforçam a idéia de que a fácies de topo Fma foi depositada durante o processo final de assoreamento do lago. Todo o processo ocorreu de forma natural sem influência de ação antrópica.
\end{abstract}

Palavras-chave: fácies Sedimentares, ambiente lacustre, médio Rio Doce, cenozóico.

\begin{abstract}
Faciologic analysis within palinological interpretation of corer record from lacustrine enviroment of the Parque Estadual do Rio Doce (Minas Gerais, Brazil). This paper describes the sedimentary facies and an enviromental interpretation of the final depositional process from $1,65 \mathrm{~m}$ of corer recovered (LPERD) in the middle Doce river valley, Minas Gerais State, Brazil. Three facies were identificated and particles of clay dominated the deposit packet indicating low energy envolved The facies can form groups in two associations: group I environment with few variation of energy and group II environment with lower variation of energy. The palinology analysis of the top facies showed two kinds of algae, five types of phytoclasts, one fungi spores, three kinds os Pteridophytas spores and 11 pollens of Angiospermy. The most are tipics of Rain Forests and some spores as of Botryococcus braunii e Spirogyra sp. from swamp. These results are according with the process of palustrine final conditions. All the depositional process ocurred in natural form without anthropic influence.
\end{abstract}

Keyworks: sedimentary facies, lacustrine enviroment, middle Doce River, cenozoic.

INTRODUÇÃO O Parque Estadual do Rio Doce (PERD) está inserido na área fisiográfica, denominada "Depressão Interplanáltica do Médio Vale do Rio Doce" (Fig. 1), que coincide com um marcante lineamento NNE-SSW apresentando foliação paralela aos contatos entre as unidades litológicas, compreendendo um complexo de gnaisses, migmatitos, granitos e granodioritos. A maior parte da região é constituída por gnaisses bandeados enriquecidos com biotitas, localmente migmatitos, onde remanescentes de cinturões de "greenstones" estão presentes. (Mello 1997, Mello et al. 1999,
Rodrigues-Filho \& Müller 1999, Castro 2001).

A região é caracterizada como "Domínio Tropical Atlântico" de "Mares de Morro" com cobertura vegetal típica de "Mata Atlântica" sendo o PERD a maior área contínua preservada desse bioma em todo o estado de Minas Gerais (Ab Saber 1977). O clima é tropical quente e úmido, com temperatura média anual entre 20 e $22{ }^{\circ} \mathrm{C}$ onde a estação seca é bem definida e as chuvas concentram-se nos meses do verão sendo em média 1.250 mm nas porções rebaixadas (Nimer 1966 apud Tundisi \& Tundisi, 1981, Rodrigues-Filho \& Müller 1999).

1 - Programa de Pós-graduação em Evolução Crustal e Recursos Naturais, Departamento de Geologia, Escola de Minas, UFOP, Ouro Preto (MG), Brasil. E-mail: cperonico@yahoo.com.br

2 - Departamento de Geologia, Escola de Minas, UFOP, Ouro Preto (MG), Brasil. E-mail: paulo_de_castro@degeo.ufop.br; ptacastro@gmail.com 


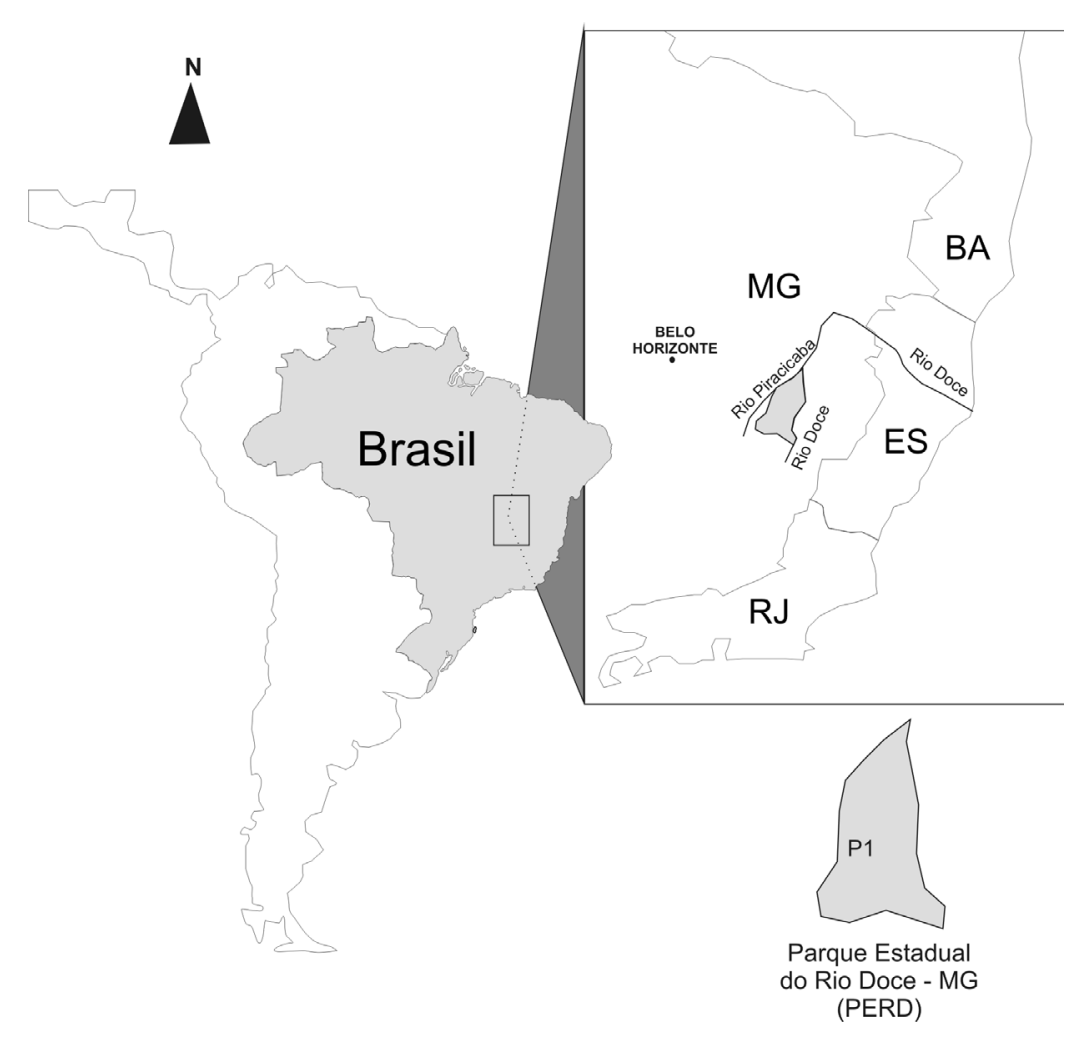

Figura 1 - Bacia do rio Doce com ênfase à sua localização e destaque para o médio vale onde se encontra o Parque Estadual do Rio Doce (PERD). O ponto P1 se refere ao local de coleta LPERD.

Destaca-se na região um complexo com mais de 130 lagos sendo que, cerca de 40 deles encontram-se nas dependências do PERD (Tundisi \& Tundisi 1981, Mello 1997). Como mecanismos condicionantes para a origem desse sistema lacustre são apontados: mudanças paleoclimáticas (Meis 1977, Meis \& Monteiro 1979, Meis \& Tundisi 1986, Pflug 1969, Ybert et al. 1997) ou neotectônica regional (Barbosa \& Kohler 1981, Mello 1997, Mello et al. 1999, Saadi 1991, Suguio \& Kohler 1992). Tais teorias são sustentadas a partir de análises faciológicas e palinológicas de testemunhos sedimentares recuperados dos lagos Dom Helvécio, Carioca, Bonita e "33" que se encontram dentro dos limites do PERD, além dos lagos Silvana, Amarelo e Jacaré localizados nos arredores dessa Unidade de Conservação.

Em se tratando da região, nenhum trabalho se propôs, ainda, a estudar os ambientes assoreados desse sistema, sejam braços lacustres ou antigos lagos. Essa carência foi o principal motivo para a apresentação deste projeto. $\mathrm{O}$ pioneirismo deste tipo de proposta vem colaborar nos estudos da evolução do Neógeno continental brasileiro, uma vez que seus resultados podem subsidiar o melhor entendimento do mecanismo de evolução dos lagos da região durante o Holoceno.

O presente trabalho consiste no resultado da análise faciológica de um testemunho sedimentar, recuperado de um ambiente lacustre já assoreado, localizado na porção sudoeste do Parque Estadual do Rio Doce, com a finalidade de descrever a história evolutiva deste ambiente durante o Holoceno. Uma análise palinológica da fácies de topo possibilitou uma interpretação preliminar da fase final do processo deposicional.

ÁREA DE ESTUDO O local onde foi recuperado o testemunho sedimentar trata-se de um ambiente em avançado estágio de assoreamento conhecido como brejão, situado próximo ao Batalhão da Polícia Militar Ambiental (portaria principal do PERD) precisamente nas coordenadas 23k 0747972/7813408 UTM (Fig. 2). Esta área encontra-se entre a Lagoa "33" (Tundisi \& Tundisi 1981) e o lago Dom Helvécio, fazendo parte, a princípio, da antiga rede de drenagem que, após o barramento, teria originado estes lagos.

MATERIAIS E MÉTODOS O testemunho de 1,65 $\mathrm{m}$ denominado LPERD foi coletado em um antigo lago, hoje completamente assoreado, onde predomina vegetação de macrófitas associadas a gramíneas. As coordenadas do ponto de coleta - 23 K 07479727813408 UTM - foram adquiridas com a utilização do Global Position System (G.P.S.) através de um equipamento da marca Garmin e modelo E-trex.

$\mathrm{Na}$ recuperação do testemunho foi aplicado o método de percussão em um tubo eletroduto de P.V.C., com 1,5" de diâmetro (Luz et al. 2005, Oliveira et al. 2004, Luz \& Barth 2000, Parizzi 1993). Uma marreta de $3 \mathrm{~kg}$ serviu de ferramenta de propulsão e para preservar a integridade do tubo um anteparo de borracha na- 


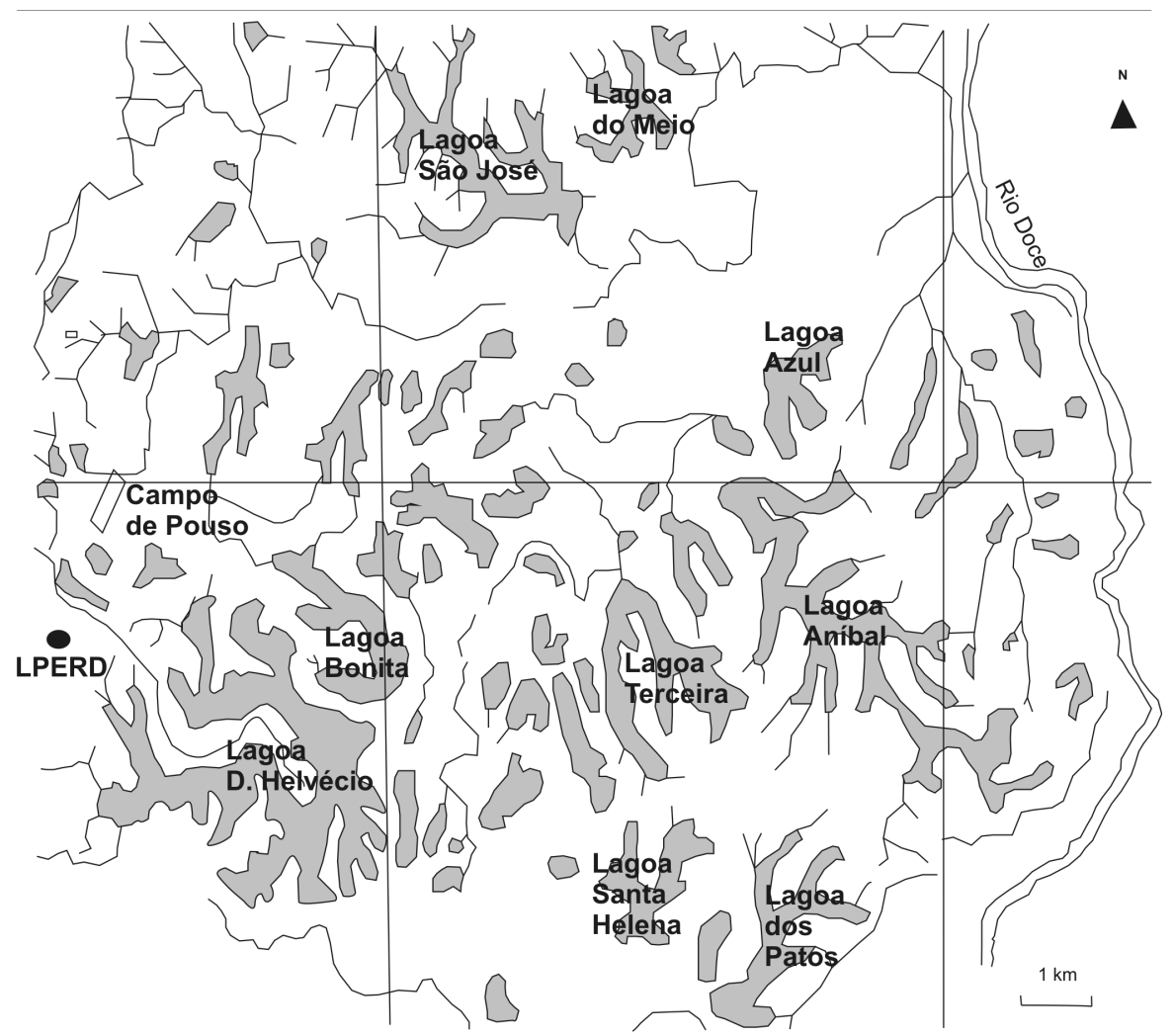

Figura 2 - Algumas das principais lagoas do complexo lacustre do médio rio Doce contidas no Parque Estadual do Rio Doce (PERD). Destaque para a localização do ponto de coleta LPERD. (Adaptado de Mello 1997).

tural do tipo M-1218 (100 x $100 \mathrm{~mm})$ funcionou como suporte de amortecimento. A remoção do eletroduto, contendo o testemunho recuperado, foi realizada com a utilização de cabos de aço. Durante este processo, foi possível produzir um ambiente de vácuo dentro do tubo, vedando sua extremidade superior com um tampão de cortiça de maneira a permitir a integridade estrutural do sedimento retido no interior do eletroduto.

Para a identificação das fácies considerou-se a definição de Selley (1982), principalmente, quando levou-se em conta a estrutura sedimentar, reconhecendo-se os parâmetros de coloração predominante e informações granulométricas. Como base bibliográfica para a determinação das cores predominantes consultou-se a tabela de cores de solos de Munsell (Munsell Soil Color Charts). Nesta etapa, o tubo de eletroduto foi cuidadosamente cortado longitudinalmente, empregandose uma serra elétrica conhecida comercialmente como "modelo tico-tico", de maneira que, depois de aberto, cada metade do tubo expôs a hemi-face sedimentar recuperada, permitindo a identificação das características estruturais externas como coloração, granulometria, bioclastos, fragmentos orgânicos, entre outros.

Uma amostra de sedimento da fácies de topo Fma foi submetida a uma adaptação da metodologia sugerida por Ybert et al. (1997) com o propósito de se recuperar e identificar os grãos de pólens, esporos e fitoclastos correspondentes ao recente ambiente de se- dimentação da área estudada. Para isso foi necessário concentrar os palinomorfos preservados no sedimento recuperado eliminando os constituintes minerais e orgânicos dispensáveis, através de uma seqüência de tratamentos físicos e químicos. Um volume amostral de $1,0 \mathrm{~cm}^{3}$ foi retirado aleatoriamente da fácies de topo Fma utilizando-se uma colher volumétrica de plástico de mesma capacidade, sendo em seguida transferido para um tubete de centrífuga de $15 \mathrm{ml}$ onde foram efetuados os processos físicos e químicos. O processo físico de centrifugação ocorreu a $2500 \mathrm{rpm}$ durante 5 minutos. Após cada adição de reagentes agitou-se o sedimento retido no fundo dos tubetes servindo-se de um palito de madeira descartável. As etapas do tratamento da amostra da fácies Fma encontram-se relacionadas a seguir: (a) Adição de $1,0 \mathrm{~cm}^{3}$ de sedimento no tubete de centrifugação; (b) Adição de $\mathrm{HCl} \mathrm{10 \%} \mathrm{para} \mathrm{dissolver}$ possíveis carbonatos, centrifugar durante 5 minutos; (c) Adição de $\mathrm{KOH} 10 \%$, centrifugar durante 5 minutos (d)

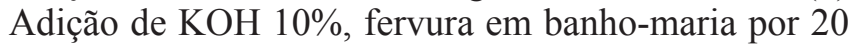
minutos para eliminar a matéria orgânica carbonizada, centrifugar durante 5 minutos. (e) Lavagem com água destilada, duas vezes. Consiste em adicionar a água destilada e centrifugar durante 5 minutos; (f) Adição de $\mathrm{HCl} 10 \%$, centrifugar durante 5 minutos; (g) Lavagem com água destilada, duas vezes.

Com o propósito de eliminar a matéria orgânica associada, principalmente celulose, destruição de 
citoplasma e estabilização da exina (membrana externa de polens e esporos) empregou-se o processo da acetólise cujas etapas são enumeradas a seguir: (a) Adição de ácido acético $10 \%$, centrifugar durante 5 minutos; (b) Adição de ácido acético P.A. para desidratar o sedimento, centrifugar durante 5 minutos; (c) Mistura de acetólise: 1 parte de ácido sulfúrico P.A. (5 ml) misturados a 9 partes de ácido anidrido acético P.A. (45 ml). Fervura em banho-maria por 10 minutos; (d) Adição de ácido acético P.A. $(2 \mathrm{ml})$ para cessar a reação, centrifugar durante 5 minutos; (e) Adição de ácido acético $10 \%$, centrifugar durante 5 minutos.

Com o término do tratamento químico e físico, transferiu-se o resíduo final contido nos tubetes para recipientes de armazenamento de vidro, com capacidade para $8 \mathrm{ml}$ e adicionou-se 5 a 10 gotas de glicerina, previamente misturada com o corante safranina que dá coloração aos polens e esporos. Em seguida, o recipiente foi colocado em estufa com temperatura de $60^{\circ} \mathrm{C}$ onde permaneceu durante 24 horas. Após esse período, o conteúdo foi homogeneizado de acordo com a recomendação de Parizzi (1993) para evitar que grãos pesados se concentrassem no fundo e os leves na superfície sendo assim, providenciada a preparação das lâminas. Com o auxílio de uma pipeta volumétrica uma gota da mistura homogeneizada foi colocada na superfície de uma lâmina, cobrindo-a em seguida com uma lamínula, de forma que o conteúdo se espalhasse por toda a sua extensão. As laterais da lamínula foram vedadas com base incolor para garantir maior durabilidade da lâmina. Estas foram analisadas em microscópio óptico, modelo Ken-A Vision TT-1500 N, sendo utilizado "charriot" com escala milimétrica em coordenadas. O aumento de $100 x$ serviu para a procura de grãos de polens e esporos. No campo de visão de 400x pôde-se ter uma melhor percepção das formas estruturais. Finalmente, o aumento de 1000x foi necessário para detalhar tipos de aberturas e presença de ornamentações, fundamentais para a identificação dentro da sistemática dos palinomorfos. Para percorrer todo o campo da lamínula o deslocamento foi realizado milímetro a milímetro, no sentido da esquerda para a direita, sucessivamente, até completar toda a área de observação. A identificação taxonômica dos grãos de pólen e esporos foi baseada nos trabalhos de Roubik \& Moreno (1991), Tyson (1995) e Garcia (1997).

RESULTADOS E DISCUSSÃO Foram recuperados $1,65 \mathrm{~m}$ de testemunho. Nele foram reconhecidas três fácies, consideradas mais relevantes, sendo que duas delas se alternaram ao longo de todo o sedimento recuperado (Fig. 3). A fração argila predominou demonstrando que o processo deposicional envolveu baixa energia permitindo a decantação das partículas assim como ocorre em um ambiente lacustre (McLane 1995). A designação das fácies identificadas foi feita mediante o emprego de letras maiúsculas representando a textura (granulometria), seguidas de letras minúsculas referindo-se às estruturas sedimentares mais relevantes, típicas da unidade, como tem sido apresentado na literatura geológica (Fernandes 1998 apud Etchebehere \& Saad 2003, Miall 1990 e 1996,

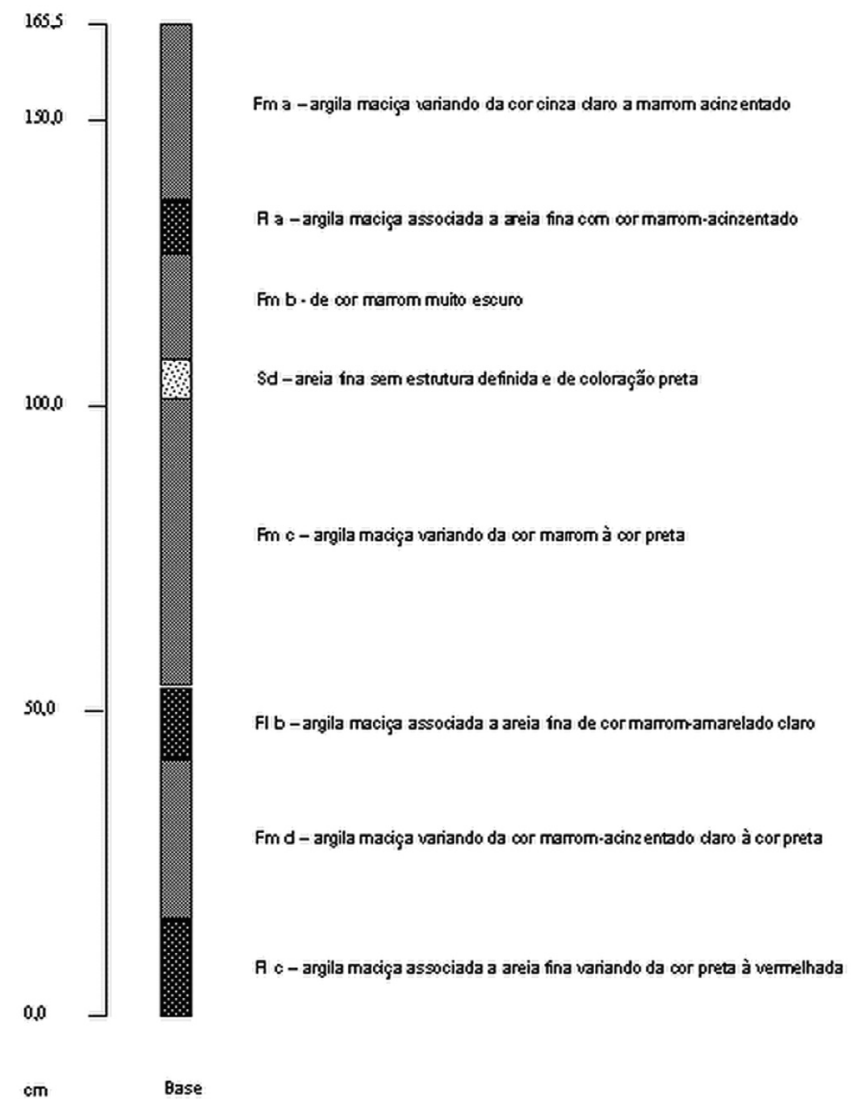

Figura 3 - Perfil do testemunho LPERD demonstrando as fácies, suas principais características macroscópicas e os respectivos comprimentos.

Santos 1997, Souza 2000, Stevaux 1993). As principais características encontram-se resumidas na tabela 1.

Meis e colaboradores (1978 e 1979) destacam eventos de transgressão e regressão durante o processo de formação dos lagos do médio rio Doce. Os resultados encontrados não apontam para que eventos destas proporções tenham atingido o lago. Tundisi \& Tundisi (1981) consoderam que pequenas flutuações do nível desse sistema de lagos é normal. Rodrigues-Filho \& Muller (1999) corroboram a idéia das pequenas margens de flutuações serem naturais do sistema quando associam a presença de areia na argila lacustre a fluxo mais intenso durante o aumento das chuvas e ao recuo lacustre durante o Holoceno. Neste trabalho, foi possível observar que fácies composta por sedimento na fração argila se alternou com aquela que apresentou uma mescla da fração argila com areia fina. Isto foi interpretado como alteração na profundidade da lâmina d'água ora mais profunda, permitindo maior acúmulo de aporte argiloso, ora diminuindo a altura da lâmina d'água possibilitando a adição de partículas na fração areia fina. Entretanto, acredita-se que durante esse período o lago era, relativamente, raso visto que a coloração em todo o pacote sedimentar variou de marrom a preto caracterizando um ambiente de pouca profundidade e anóxico como relatam Rodrigues-Filho \& Müller (1999).

Estudos sedimentológicos no médio vale do rio 
Doce foram realizados, sobretudo, na tentativa de se explicar a origem do Sistema Lacustre da região (Meis \& Machado 1978, Meis \& Monteiro 1979, Mello 1997 e 1999, Rodrigues-Filho \& Müller 1999, Saadi 1991). Em nenhum deles, foi identificada, durante a fase lacustre dos testemunhos estudados, uma fácies constituída essencialmente por sedimento na fração areia fina como a que forma a fácies $S d$ (Tab. 1). A situação desta fácies é considerada aqui, anômala, em um contexto ambiental marcado por sedimentação, predominantemente, de menor fração. A coloração escura da areia fina encontrada nessa fácies, associada à ausência de estrutura sedimentar definida aponta para um momento de anoxia elevada (Rodrigues-Filho \& Müller 1999) com lâmina d'água tão baixa que expusera o ambiente a receber partículas exógenas de maior fração, mas não possibilitou a decantação de sedimento argiloso.

Rodrigues-Filho \& Muller (1999) afirmam que o pacote sedimentar demonstra o grau de desagregação (erosão) da matriz fonte. Dessa forma, o pacote sedimentar estudado comporta informações da área que funcionou como fonte para a sua formação. O latossolo, da região, vermelho-amarelado e os podizólitos de mesma coloração (definidos por Meiss 1977 e Camargo et al. 1966 apud Tundisi \& Tundisi 1981) estiveram representados no sedimento recuperado. A coloração escura encontrada em todo o testemunho, pois, corrobora a idéia da associação de material autóctone de natureza orgânica, em um ambiente lacustre relativamente raso, onde predominou a fase anóxica.

Foi possível reconhecer dois conjuntos de fácies do testemunho LPERD (Tab. 2). Etchebehere \& Saad (op. cit) enquadram as associações de fácies estudadas em três categorias principais: fácies deposicionais (stricto sensu), fácies residuais (cascalho de origem eluvionar) e fácies de liquefação (indícios de atividade sísmica). Todas as fácies identificadas em LPERD podem ser agrupadas em um conjunto maior de fácies deposicionais propriamente ditas. A associação I foi interpretada como um ambiente com ligeira diminuição da energia de deposição enquanto na associação II, possivelmente, ocorreu uma diminuição mais significativa. Ambas as associações, no entanto, não descartam a possibilidade de todo o processo deposicional ter ocorrido em um ambiente alagado.

A análise palinológica da fácies Fma (topo) permitiu uma interpretação preliminar da fase final do processo de deposição. Foram identificados dois tipos de algas, cinco tipos de fitoclastos, um tipo de esporo de fungo, três tipos de esporos de pteridófitas e 11 tipos de grãos de pólen de angiospermas. Os pólens encontrados pertencem à táxons de ocorrência registrada para a Floresta Estacional Semidecídua Submontana que corresponde ao tipo vegetacional que compõe a Mata Atlântica da região estudada (Rodrigues-Filho \& Muller 1999, Veloso et al. 1991, Ybert et al. 1997). As algas identificadas pertencem às espécies Botryococcus braunii e Spirogyra sp. que, de acordo com Garcia (1997), ocupam pântanos rasos, solos encharcados ou úmidos, além de, turfeiras. Tais características estão em concordância com o ambiente palustre que se conota à área durante o período de deposição dessa fácies. Foram encontrados na amostra fitoclastos opacos, de cor preta que, de acordo com os autores supracitados representam estruturas de tecido preservadas como resultado da queima de incêndio natural. Estas evidências são, portanto, atribuídas a vestígios de um incêndio, ocorrido na segunda metade do século passado, que atingiu a área estudada (Tundisi \& Tundisi 1981). De acordo com Garcia (1997), o registro de esporos de fungos é

Tabela 1 - Classificação das fácies: $m$ - estrutura maciça, compacta; $l$-disposição laminar do sedimento; $d$-ausência de estrutura definida.

\begin{tabular}{|c|c|c|c|c|}
\hline Fácies & Comprimento & $\begin{array}{l}\text { Características } \\
\text { texturais }\end{array}$ & $\begin{array}{c}\text { Estruturas } \\
\text { sedimentares }\end{array}$ & $\begin{array}{c}\text { Coloração } \\
\text { (Munsell 2000) }\end{array}$ \\
\hline Fm a & $37 \mathrm{~cm}$ & Argila & Maciça & $\begin{array}{c}2,5 \mathrm{Y} 3 / 2 \text { marron acinzentado a } \\
2,5 \mathrm{Y} 7 / 2 \text { cinza claro }\end{array}$ \\
\hline $\mathrm{Fl} \mathrm{a}$ & $5,4 \mathrm{~cm}$ & Argila e areia fina & $\begin{array}{c}\text { Maciça com laminação } \\
\text { de areia fina }\end{array}$ & $2,5 Y$ Y $/ 2$ marron acinzentado \\
\hline $\mathrm{Fm} \mathrm{b}$ & $19,2 \mathrm{~cm}$ & Argila & Maciça & 10YR $2 / 2$ marron muito escuro \\
\hline $\mathrm{Sd}$ & $2,3 \mathrm{~cm}$ & Areia fina & desestruturada & 10YR 2/1 preto \\
\hline Fm c & $49,6 \mathrm{~cm}$ & Argila & Maciça & $10 \mathrm{YR} 5 / 3$ marron a $10 \mathrm{YR} 2 / 1$ preto \\
\hline $\mathrm{Fl} \mathrm{b}$ & $13,1 \mathrm{~cm}$ & Argila e areia fina & $\begin{array}{l}\text { Maciça com laminação } \\
\text { de areia fina }\end{array}$ & $2,5 \mathrm{Y} 6 / 4$ marron amarelo claro \\
\hline Fm d & $29,5 \mathrm{~cm}$ & Argila & Maciça & $\begin{array}{l}\text { 10YR marron acinzentado escuro a } \\
5 \mathrm{Y} 2 / 2 \text { preto }\end{array}$ \\
\hline $\mathrm{Fl} \mathrm{c}$ & $8,9 \mathrm{~cm}$ & Argila e areia fina & $\begin{array}{c}\text { Maciça com laminação } \\
\text { de areia fina }\end{array}$ & $\begin{array}{c}5 \mathrm{Y} 2 / 1 \text { preto a } \\
10 \mathrm{YR} 7 / 6 \text { vermelho }\end{array}$ \\
\hline
\end{tabular}


Tabela 2 - Associações de fácies estabelecidas para o testemunho LPERD.

\begin{tabular}{c|c|c|c|c}
\hline Caráter das Fácies & Conjunto de fácies & $\begin{array}{c}\text { Associações de } \\
\text { Fácies }\end{array}$ & Observações & Interpretação \\
\hline \multirow{2}{*}{$\begin{array}{c}\text { Fácies sedimentares } \\
\text { deposicionais strito }\end{array}$} & Fl a - Fma & I & $\begin{array}{c}\text { Associação passando } \\
\text { de areia fina e argila } \\
\text { para somente argila com } \\
\text { diminuição branda da } \\
\text { energia de deposição }\end{array}$ & $\begin{array}{c}\text { Ambiente lacustre em } \\
\text { processo de aumento gradual } \\
\text { da lâmina d'água }\end{array}$ \\
\cline { 2 - 5 } & Fl - Fm b - Fm c & II & $\begin{array}{c}\text { Associação passando de } \\
\text { areia fina para argila com } \\
\text { diminuição acentuada da } \\
\text { energia de deposição }\end{array}$ & $\begin{array}{c}\text { Ambiente lacustre muito } \\
\text { raso a palustre em processo } \\
\text { moderado de aumento da } \\
\text { lâmina d'água }\end{array}$ \\
\cline { 2 - 5 } & Fl c-Fm d & I & $\begin{array}{c}\text { Associação passando } \\
\text { de areia fina e argila } \\
\text { para somente argila com } \\
\text { diminuição branda da } \\
\text { energia de deposição }\end{array}$ & $\begin{array}{c}\text { Ambiente lacustre em } \\
\text { processo de aumento gradual } \\
\text { da lâmina d'água }\end{array}$ \\
\cline { 2 - 5 } & I & $\begin{array}{c}\text { Associação passando } \\
\text { de areia fina e argila } \\
\text { para somente argila com } \\
\text { diminuição branda da } \\
\text { energia de deposição }\end{array}$ & $\begin{array}{c}\text { Ambiente lacustre em } \\
\text { processo de aumento gradual } \\
\text { da lâmina d'água }\end{array}$ \\
\hline
\end{tabular}

indicativo de solos orgânicos, anóxicos, onde o processo de decomposição foi interrompido ou ocorre de maneira muito lenta. Este mesmo autor aponta para o fato de que as espécies de pteridófitas aqui identificadas são relacionadas a margens úmidas ou solos orgânicos úmidos. Todas estas informações reforçam a idéia de que a fácies de topo Fma foi depositada durante o processo final de assoreamento do lago.

CONCLUSÕES A análise integrada dos dados obtidos do testemunho LPERD, permitiu definir, que durante o período de sua deposição, o ambiente pretérito funcionou como um lago, relativamente raso, com alternâncias do nível da coluna d'água que culminou com uma fase palustre característica de etapa avançada de assoreamento pela qual vem sendo submetida à área estudada.

$\mathrm{O}$ pacote sedimentar recuperado foi formado a partir de sedimentos provenientes de áreas fontes dos próprios arredores, uma vez que, as características sedimentares são compatíveis com o latossolo da região de entorno.
Acredita-se, que todo esse processo tenha ocorrido em condições fito-fisionômicas muito similares às atuais, onde os registros palinomórficos foram aqueles esperados tanto para Floresta Estacional Semidecídua Submontana, complexo vegetativo que recobre hoje a região, como, também, para ambientes aquáticos anóxicos. Nenhum registro exótico foi encontrado, nem mesmo das vegetações de eucalipto (monocultura) e gramíneas (pasto) que se encontram na região perimetral do PERD.

Conclui-se, pois, que esta área tenha funcionado como um lago raso, com pequenas alterações no seu nível d'água, com vegetação de borda similar à atual e em fase final de assoreamento, sendo este um processo natural dentro do sistema de lagos regional, onde as ações antrópicas de entorno não tiveram influência na área estudada.

Agradecimentos Ao suporte financeiro da $\mathrm{CNPq}$ e à infra-estrutura do Departamento de Geologia da Escola de Minas da UFOP.

\section{Referências}

Ab'Saber A.N. 1977. Espaços ocupados pela expansão dos climas secos na América do Sul, por ocasião dos períodos glaciais quaternários. Paleoclimas, 3:1-19p.

Barbosa G.V. \& Kohler H.C. 1981. O sistema lagunar do Parque do Rio Doce (MG). Boletim SBG/MG, 2:37-46.

Castro P.T.A. 2001. Origem e evolução dos lagos do médio rio Doce: perspectiva geológica. Disponível em: www. degeo.ufop.br/intranet/Graduacao/disciplinas/estratigrafia/perd.htm. Acessado em 29/04/2008.

Etchebehere M.L. \& Saad A.R. 2003. Fácies e associações de fácies em depósitos neoquaternários de terraço na bacia do rio do Peixe, região ocidental paulista. São Paulo. UNESP Geociências, 22(1):5-16.

Garcia M.J. 1997. Palinologia de turfeiras quaternárias do médio rio Paraíba do Sul, estado de São Paulo, Brasil. Parte I: Fungos, Algas Briófitas e Pteridófitas. Revista Universidade Guarulhos: Geociências II, (n especial), p. 148-165.

Luz C.F.P., Barth O.M., Silva C.G. 2005. Spatial distribuition of palynomorphs in the surface sediments of the Lagoa 
do Campelo lake, North region of Rio de Janeiro State, Brazil. Acta Bot. Bras., 19(4)741-752.

Luz C.F.P. \& Barth O.M. 2000. Palinomorfos indicadores de tipos de vegetação em sedimentos holocênicos da lagoa de Cima, norte do estado do Rio de Janeiro, Brasil - Dicotyledoneae. Leandra, 5:11-34.

Meis M.R.M. 1977. As unidades morfoestratigráficas neoquaternárias do médio vale do rio Doce. Anais da Academia Brasileira de Ciências, 49(3):443-459.

Meis M.R.M. \& Tundisi J.G. 1986. Geomorphology and limnological processes as a basis for lake typology: the middle Rio Doce Valley Lake System. Anais da Academia Brasileira de Ciências, 58:103-120.

Meis M.R.M. \& Machado M.B. 1978. A morfologia de rampas e terraços no Planalto do Sudeste do Brasil (médio vale do rio Doce). Finisterra, 13(26):199-219.

Meis M.R.M. \& Monteiro A.M.F. 1979. Upper Quaternary "rampas": Doce river valley, Southeastern Brazilian plateau. Z. Geomorph., 23(2):132-151.

Mello C.L. 1997. Sedimentação de tectônica cenozóicas no médio vale do rio Doce (MG, sudeste do Brasil) e suas implicações na evolução de um sistema de lagos. Tese de Doutoramento, Instituto de Geociências, Universidade de São Paulo, 275p.

Mello C.L., Metelo C.M.S., Suguio K., Kohler H.C. 1999. Quaternary sedimentation, neotectonics and the evolution of the Doce river middle valley lake system (southeastern Brazil). Revista do Instituto Geológico IG São Paulo, 20(1/2):29-36.

McLane M. 1995. Sedimentology. Nova Yorque, Oxford University Press, Inc., 493p.

Miall A.D. 1990. Principles of sedimentary basin analisys. $2^{\mathrm{a}}$ ed. New York, Springer-Verlag, 451p.

Miall A.D. 1996. The geology of fluvial deposits. Berlin, Springer-Verlag, 582p.

Oliveira A.D., Mendonça Filho J.G., Carvalho M.A., Menezes T.R., Lana C.C., Brenner W.W. 2004. Novo método de preparação palinológica para aumentar a recuperação de dinoflagelados. Revista Brasileira de Paleontologia. 7(1): xx-yyp.

Parizzi M.G. 1993. A gênese e a dinâmica da Lagoa Santa com base em estudos palinológicos, geomorfológicos e geológicos de sua bacia. Dissertação de Mestrado em Geologia, Belo Horizonte: Universidade Federal de Minas Gerais.

Pflug R. 1969b. Quaternary lakes of Eastern Brazil. Photogrammetria, 24:29-35.

Rodrigues-Filho S. \& Müller G. 1999. A holocene sedimen- tary record from Lake Silvana, SE Brazil: evidence for paleoclimatic changes from mineral, trace metal and pollen data. Berlin; Heidelberg; New York; Barcelona; Hong Kong; London; Milan; Paris; Singapore; Tokyo: Springer.

Roubik D.W. \& Moreno E. 1991. Pollen and spores of Barro Colorado island. Monographs in Systematic Botany 36. Missouri Botanical Garden, St Louis, MO.

Saadi A. 1991. Ensaio sobre a morfotectônica de Minas Gerais. Tese de Professor Titular, Instituto de Geociências, Univ. Federal de Minas Gerais, Belo Horizonte, 285p.

Santos L.S. 1997. Estratigrafia e evolução do sistema siliciclástico do rio Paraná no seu curso superior: ênfase à arquitetura dos depósitos, variação longitudinal das fácies e processos sedimentares. Tese de doutoramento, Univ. Federal do Rio Grande do Sul, P. Alegre, 2v.

Selley R.C. 1982. Ancient sedimentary enviroments. $2^{\mathrm{a}} \mathrm{ed}$. Cornell University Press, Ithaca, New York.

Souza I.A. 2000. Mudança no canal do rio Paraná durante o Holoceno. Dissertação de mestrado, Instituto de Geociências e Ciências Exatas, UNESP, Rio Claro, 139p.

Stevaux J.C. 1993. O rio Paraná: geomorfogênese, sedimentação e evolução quaternária do seu curso superior (região de Porto Rico, PR). Tese de doutoramento, Instituto de Geociências, Universidade de São Paulo, 243p.

Suguio K. \& Kohler H.C. 1992. Quaternary barred lake systems of the Doce river (Brazil). Anais da Academia Brasileira de Ciências, 64(2):183-191.

Tundisi J.G. \& Tundisi T.M. 1981. Estudos limnológicos no sistema de lagos do médio rio Doce, Minas Gerais, Brasil. In: Seminário Regional de Ecologia, 2, São Carlos, Anais, p. 133-258.

Tyson R.V. 1995. Sedimentary organic materr: organic facies and palynofacies. London:Chapman \& Hall, 615p.

Veloso H.P., Rangel Filho A.L.R., Lima J.C.A. 1991. Classificação da vegetação brasileira, adaptada a um sistema universal. Rio de janeiro: IBGE, $124 \mathrm{p}$.

Ybert J.P., Albuquerque A.L.S., Turcq B. 1997. Evolução paleoclimática e paleoambiental na região do vale do rio Doce (Minas Gerais, Brasil). In: Congresso da Associação Brasileira de Estudos do Quaternário, 4, Curitiba, Resumos Expandidos, p.511-514.

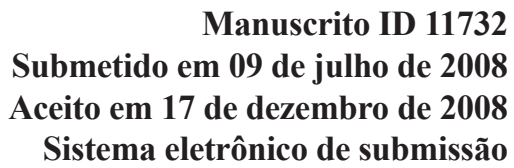

